\title{
Factors influencing online health information seeking behaviour among patients in Kwahu West Municipal, Nkawkaw, Ghana.
}

\author{
Richmond D. Nangsangna ${ }^{1,2}$, Frances da-Costa Vroom ${ }^{3 *}$ \\ ${ }^{1}$ School of Public Health, College of Health Sciences, University of Ghana \\ ${ }^{2}$ District Health Directorate, Kwahu Afram Plains South, Ghana Health Service, Eastern Region, Ghana \\ ${ }^{3}$ Biostatistics Department, School of Public Health, College of Health Sciences, University of Ghana
}

\begin{abstract}
Over the years, health care delivery and ways of accessing health information have transformed rapidly through the use of technology. The internet has played a key role in this advancement by serving as an important source of health information to people regardless of their location, language or condition.

This cross sectional study was conducted in the Kwahu West Municipal to determine factors influencing online health information seeking behaviours among patients. Three hospitals in the municipality were purposively selected for the study. Outpatients attending these facilities were systematically selected and data was collected using structured interviewer administered questionnaire.

The study findings revealed that internet usage rate among patients was $85.8 \%$. However, only $35.7 \%$ of patients ever used the internet to access health information. Sex, education and average monthly income were significant factors associated with online health information seeking. The study also showed that, computer and internet experience factors increased the probability of using internet for health information. After adjusting for confounding factors; being employed, earning higher income and owning a computer were positive predictors of online health information seeking.

It is important to explore other means of reducing the disparity in information access by improving skill and health literacy among the low social class who cannot afford internet ready devices. Health care providers should recognize that patients are seeking health information from the internet and should be prepared to assist and promote internet user skills among their patients.

Keywords: Internet, Online Health Information Seeking Behaviour

* Corresponding author: Frances da-Costa Vroom: email: fbvroom@ug.edu.gh

DOI: 10.5210/ojphi.v11i2.10141

Copyright @2019 the author(s)

This is an Open Access article. Authors own copyright of their articles appearing in the Online Journal of Public Health Informatics. Readers may copy articles without permission of the copyright owner(s), as long as the author and OJPHI are acknowledged in the copy and the copy is used for educational, not-for-profit purposes.
\end{abstract}




\section{Introduction}

The internet is defined as a global network of computers and other communication gadgets that enables communication directly and transparently. It is commonly said to be a network of networks or network of computers. It is also said to be a system for information sharing and a means for interaction between individuals and communication devices regardless of their location. Lately, internet use has been said to be increasing rapidly and the vast increase, can be attributed to rapid evolvement in Information and Communication Technology (ICT), availability of information and affordability to access [1].

In the past, people obtained health information by visiting the library, consulting a health care professional or speaking to trusted associates. The phenomenon has since changed due to the rapid evolvement of information technology [2]. The internet serves as a major source of health information for both professional and private reasons. According to the World Health Organization, many individuals especially in the developed world, access online health information, participate in online communities and buy products and services for health and wellbeing. On the other side, records of patients are also networked by health institutions $[3,4]$. This has led to new forms of risk such as sale and use of health data of individuals and groups. Individuals also are at risk of poor health due to counterfeit, adulterated and unapproved drugs trade, and other products that are illegally promoted by some internet sources [5].

Research has indicated that, there has been a $20 \%$ increase in internet users, with $80 \%$ of adult Internet users in the US (93 million) using the Internet to obtain health-related information [6]. Online health information seeking is on the increase and information obtained has varied impacts on the health outcomes of individuals. Apart from the development in ICT, individuals desire to contribute to their health and to reduce cost of care is known to be a contributing factor [7]. It has the potential of bridging the gap of inadequate access to health care especially in rural areas with limited health resources.

The search for health information via the internet is fast growing among all health stakeholders. For example, studies show that the use of internet by elderly people in China is increasing rapidly as it is considered convenient and meets their needs [6]. In the USA and Europe, about $72 \%$ and $71 \%$ of internet users conduct health related searches. Availability and access to health information online is known to empower patients and improve physician and patient relationship to be more participatory. The development is known to have positive impact as patients who are adequately informed of their condition, tend to have better adherence to treatment. It also has the potential of reducing health care cost [2]. A study conducted among patients visiting the surgical care department of a tertiary hospital in Ghana, revealed that among 35.7\% of patients who had access to the internet, only $30.4 \%$ of them were aware of the availability of health information related to their disease condition on the Internet. Subsequently, only $15.7 \%$ had visited the internet to access health information concerning their condition [8].

\section{Characteristics of online health information seekers}

Several studies conducted in developed countries have found a lot of characteristics of online health information seekers, which include socio-demographic and health related characteristics. 
Age is one of such characteristics. Patients who use the internet for health related purposes are middle-aged and older people, females, more educated individuals and people with internet usage skills [9]. Little is known about the behaviours and characteristics of online health information seekers in developing countries especially in Africa. These could help understand the needs of online health seekers as well as the factors that affect their search and use of information [9]. Also, in spite of the large health information that exists on the internet, there is little consistency in terms of how many people actually use this information, if it meets their expectations, and the implications of this usage [9]. There are many reasons why people should seek health information from the internet however, they may not utilize this resource as much as they should [10]. Several factors have been identified as influencing the search for health information online. For example, access to internet and search for health information in Ghana is said to be affected by unreliable and slow internet connection, high cost of Internet service, and unreliable power supply [1]. A study among Nigerian University students also revealed that, $42 \%$ of the respondents perceived the cost of internet access as a major constraint to accessibility of information via the internet as well as erratic power supply [10].

In Ghana, doctor to population ratio as at 2017 was 1:7374 [12]. This is above the WHO recommendation of 1:1000. This is especially, worsened by the unequal distribution of few health care facilities in the country. It is therefore imperative that, individuals will resort to the internet for health information in order to avoid the pressures of accessing care through the few facilities and staff available. Few studies however, have investigated individuals' online health information seeking behaviour. The few identified have focused on students and urban dwellers $[1,11,13]$. Access to internet in Ghana has greatly increased especially through widespread telecommunication networks and use of smart phones across all areas; urban, semi-urban and rural [14]. It presupposes that, rural dwellers may be having similar online health seeking behaviours as their urban counterparts. However, little is known about online health seeking behaviours among rural or semi-urban dwellers in Ghana. This study therefore seeks to identify factors influencing online health information seeking behaviours among patients in a semi-urban and rural district in Ghana.

\section{Methods}

\section{Study Area}

The study was conducted in Nkawkaw, the Administrative Municipal capital of the Kwahu West Municipality. Kwahu West Municipal forms part of the twenty six (26) Municipalities and Districts in the Eastern Region of Ghana, with a total land size of $401 \mathrm{~km}^{2}$. The Municipality is commercial and cosmopolitan with its capital, Nkawkaw, located about 241 kilometres NorthWest of Accra.

The municipality had a total projected population of about 114,409 in 2018 . Of the population 11 years and older, 87.0 percent are literate. The proportion of literate males is higher $(92.0 \%)$ than that of females $(82.5 \%)$. According to the 2010 national population and housing census report, fifty-five percent (55.0\%) of individuals 12 years and older in the municipality, own mobile phones of which males constitute $59.2 \%$. About seven percent $(6.6 \%)$ of the population who are 12 years 
and older use internet facilities in the municipality. Only six percent of the total households in the municipality have desktop/laptop computers.

The Municipality is divided into eleven (11) Sub-Municipals with fifty (50) health facilities. The health facilities comprise of 36 government owned community-based health planning and services (CHPS) and 9 health centres, 2 private maternity homes, two private hospitals (Kenop Care Hospital and Agyakwa Hospital) and one faith-based hospital (Holy Family Hospital). According to the District Health Annual Performance Report 2017, the annual institutional OPD attendance rate saw the three hospitals with major coverage of $78 \%$ (Holy Family Hospital $=57 \%$, Kenop Care Hospital $=31 / \%$ and Agyakwa $=12 \%$ ).

\section{Study design and population}

This was a descriptive cross sectional quantitative study conducted among outpatients attending the three hospitals in the municipality. The study involved all outpatients seeking health care at hospitals in the Kwahu West Municipality.

Outpatients visiting the three health facilities (Kenop Care Hospital, Agyakwa Hospital and Holy Family Hospital), on days of data collection qualified to be part of the study. Patients attending health facility for the first time, emergency cases, and patients who were too ill were excluded from the study.

\section{Sample size determination}

Using the formula adopted from Cochran [14] for descriptive cross sectional studies,

i.e. $n=\frac{Z^{2} P(1-P)}{d^{2}}$ (where $\mathrm{n}=$ estimated sample size, $\mathrm{Z}=$ Standard value for $95 \%$ confidence level; 1.96, $\mathrm{p}=$ estimated proportion of patients who access health information online from a previous study; $15.7 \%$ (8) and $d=$ margin of error; (0.05), a total of 204 patients were recruited for the study.

\section{Sampling procedure}

Three hospitals which are Holy family hospital, Agyakwa hospital and Kenop Care hospital, all in the municipality were purposively selected for the study. Proportionate sampling method was used to determine number of outpatients to be interviewed from each hospital based on the OPD institutional attendance rate (57\% from Holy family hospital, 31\% from Kenop Care Hospital and $12 \%$ from Agyakwa Hospital). At the hospitals, systematic sampling method was used to select outpatients. During the visit, the day's records of outpatients containing serial numbers/outpatient record numbers which are documented in the outpatient register, was used. Using the total sample size divided by each facility sample size, an interval of 2, 3 and 8 was obtained for Holy Family Hospital, Kenop Care Hospital and Agyakwa Hospital respectively. Randomly selecting a record number from the day's outpatient register as the $1^{\text {st }}$ patient, other outpatients were selected using the obtained intervals. Selected patients who agreed to be interviewed were recruited and questionnaires administered by the interviewer. This was done in each hospital until the desired sample size for the study was achieved. 


\section{Data collection procedure}

Data was collected from respondents using a structured questionnaire administered by the researcher. To avoid interruptions, interviews were conducted by researcher after patients had completed their visit or were not being engaged by health care providers. A private place was identified in each hospital, to conduct interviews. This was to ensure confidentiality and genuine responses.

\section{Data collection tools}

A structured questionnaire was used to collect data from patients. The questionnaire contained close-ended questions and a few Likert type questions. The questionnaire included questions on patient background and clinical characteristics as well as patients' computer and internet experience.

\section{Quality control}

Questionnaires for data collection were reviewed by the research supervisor after they were designed by the researcher. Pre-testing of the questionnaire was conducted at Kwahu Government hospital, located at the capital of Kwahu South District; Atibie, a neighbouring district. All errors identified in the questionnaires were corrected before a final copy was printed for use. One participant was entitled to answer only one questionnaire. Questionnaires were checked daily to ensure accuracy and completeness.

\section{Data processing and analysis}

To ensure easy data entry, each question was assigned a code. Completed questionnaires were entered into the IBM Statistical Package for Social Sciences (SPSS) version 21 software. After data entry, the data was verified and cleaned to eliminate errors and ensure completeness. The cleaned data was then exported to Stata SE v.13 for analysis. Quantitative variables were summarized using measures of central tendency, specifically mean and standard deviation. Categorical variables were summarized using frequencies and percentages. For comparison, bivariate analysis was conducted using chi-square test to determine patient characteristics that influence online health information seeking. Logistic regression model was used to determine patient factors that affect use of online health information. A significance level of $95 \%$ was used with $\alpha=0.05$. Results were then presented in tables.

\section{Ethical considerations}

Approval to conduct the study was sought from administrators of the various hospitals. Informed consent was obtained from study participants. Participants signed or thump-printed the consent forms prior to completing the questionnaire. Participants were adequately informed about their right to refuse to participate in the study and opt out at any time if they wished to do so. Participants' privacy, confidentiality and anonymity were protected. 


\section{Results}

\section{General characteristics of study population}

Recruitment efforts resulted in a total of 204 participants. The ages of study participants ranged from 16 to 94 years (Mean $=37.7$ years, $\mathrm{SD}=13.5$ ). The highest proportion was in the age category below 30 years $(34.8 \%)$. More than half of the participants $(58.3 \%)$ were married, with majority (37.3\%) having 1 to 2 children. Almost three quarters $(72.5 \%)$ of participants were Christians, $24.5 \%$ belonged to the Islamic religion whilst $1.5 \%$ were traditionalists or do not believe or practice any religion. Majority of participants (48\%) had secondary education, $34.3 \%$ had tertiary education whilst $7.4 \%$ had no formal education. Over half of the participants $(54.4 \%)$ were employed, $18.6 \%$ were unemployed with $2.5 \%$ having retired from active service. Over one quarter (28.4\%) had monthly income between 500 and 1000GHS, 26\% below 500GHS, and $17.6 \%$ had income $\geq 1000 \mathrm{GHS}$. The proportion of participants who were registered on the national health insurance scheme were $94.6 \%$ and $20.1 \%$ were on other health insurance policies.

Clinical history revealed that $74.0 \%$ of participants did not have any chronic illness, $21.1 \%$ had one chronic illness and only $5.4 \%$ had two or more chronic illnesses. Twenty-four percent of participants reported they had no friend or relative with chronic illness. On frequency of visits made by participants to clinician in the past six months, 32.8\% reported visiting 1 to 2 times, $19.1 \%$ visited more than 5 times and $43 \%$ perceived their personal health status as very good.

\section{Health information seeking and the internet}

Out of $175(85.78 \%)$ participants who have ever used the internet, sixty-four of the participants $(31.37 \%)$ reported that they have ever used the internet for seeking health information. Details are provided in Table 1.

Table 1: Participants use of internet for health information

\begin{tabular}{lll}
\hline Variable & Frequency (N=204) & Percentage (\%) \\
\hline Ever used the internet & 175 & 85.78 \\
Yes & 29 & 14.22 \\
No & & \\
Ever used internet for Health information & & 31.37 \\
Yes & 64 & 68.63 \\
No & 140 & \\
\hline
\end{tabular}




\section{Socio-demographic factors and health information seeking using the internet}

At a significance level $\leq 0.05$, sex $(\mathrm{p}=0.037)$, level of education $(\mathrm{p}<0.0001)$, employment status $(\mathrm{p}<0.0001)$, average monthly income $(\mathrm{p}=0.001)$ and membership on other insurance policy $(\mathrm{p}=0.002)$ were found to be significantly associated with the use of internet for health information purposes (Table 2).

Table 2: Distribution of socio-demographic factors and use of internet for health information.

\begin{tabular}{|c|c|c|c|c|c|}
\hline \multirow[t]{2}{*}{ Socio-demographic factors } & \multicolumn{4}{|c|}{ Ever used internet for HI } & \multirow[b]{2}{*}{ Significance } \\
\hline & Yes & $\%$ & No & $\%$ & \\
\hline \multicolumn{6}{|l|}{ Sex } \\
\hline Male & 37 & 57.81 & 59 & 42.14 & \multirow{2}{*}{$\begin{array}{l}x^{2}=4.33 \\
P=0.037^{*}\end{array}$} \\
\hline Female & 27 & 42.19 & 81 & 57.86 & \\
\hline \multicolumn{6}{|l|}{ Age (years) } \\
\hline$<30$ & 22 & 34.38 & 49 & 35.00 & \multirow{3}{*}{$\begin{array}{l}x^{2}=1.14 \\
\mathrm{P}=0.767\end{array}$} \\
\hline $30-39$ & 18 & 28.13 & 38 & 27.14 & \\
\hline $40-49$ & 10 & 15.63 & 29 & 20.71 & \\
\hline \multicolumn{6}{|l|}{$\begin{array}{l}\geq 50 \\
\text { Marital status }\end{array}$} \\
\hline Married & 37 & 57.81 & 82 & 58.57 & \multirow{3}{*}{$\begin{array}{l}x^{2}=1.99 \\
\mathrm{P}=0.574\end{array}$} \\
\hline Single & 18 & 28.13 & 41 & 29.29 & \\
\hline Divorced/Separated/Widowed & 8 & 12.50 & 11 & 7.86 & \\
\hline \multicolumn{6}{|l|}{ Parental status } \\
\hline No children $<15$ years & 22 & 34.38 & 46 & 32.86 & \multirow{3}{*}{$\begin{array}{l}x^{2}=0.35 \\
\mathrm{P}=0.842\end{array}$} \\
\hline $1-2$ children $<15$ years & 22 & 34.38 & 54 & 38.57 & \\
\hline 3 or more children $<15$ years & 20 & 31.25 & 40 & 28.57 & \\
\hline \multicolumn{6}{|l|}{ Level of education } \\
\hline No formal education & 0 & 0.00 & 15 & 10.71 & \multirow{3}{*}{$\begin{array}{l}x^{2}=29.89 \\
P=0.000^{*}\end{array}$} \\
\hline Primary & 0 & 0.00 & 21 & 15.00 & \\
\hline Secondary & 28 & 43.75 & 70 & 50.00 & \\
\hline Tertiary & 36 & 56.25 & 34 & 24.29 & \\
\hline \multicolumn{6}{|l|}{ Employment status } \\
\hline Employed & 42 & 65.63 & 69 & 49.29 & \multirow{3}{*}{$\begin{array}{l}x^{2}=21.73 \\
P=0.000^{*}\end{array}$} \\
\hline Unemployed & 4 & 6.25 & 34 & 24.29 & \\
\hline Retired & 0 & 0.00 & 5 & 3.57 & \\
\hline Student & 3 & 4.69 & 19 & 13.57 & \\
\hline Student and Employed & 15 & 23.44 & 13 & 9.29 & \\
\hline \multicolumn{6}{|l|}{ Average monthly income } \\
\hline$>500$ & 11 & 18.97 & 42 & 47.19 & \multirow{3}{*}{$\begin{array}{l}x^{2}=15.15 \\
P=0.001^{*}\end{array}$} \\
\hline $500-1000$ & 25 & 43.10 & 33 & 37.08 & \\
\hline$>1000$ & 22 & 37.93 & 14 & 15.73 & \\
\hline \multicolumn{6}{|l|}{ Registered with NHIS } \\
\hline Yes & 5 & 7.81 & 6 & 4.29 & $x^{2}=1.07$ \\
\hline & \multicolumn{4}{|c|}{ Registered on other policy } & $P=0.301$ \\
\hline Yes & 43 & 67.19 & 120 & 85.71 & $x^{2}=9.39$ \\
\hline No & 21 & 32.81 & 20 & 14.29 & $P=0.002^{*}$ \\
\hline
\end{tabular}




\section{Use of internet for health information and clinical history}

Results in Table 3 revealed that none of the studied clinical factors has a significant effect on seeking health information using the internet. However, proportion of participants who used the internet for health information was higher among those who have a known chronic disease, those who indicated they have only one chronic disease, participants who have a friend or a relative with a known chronic disease as well as participants who perceived their health status as very good.

Table 3: Participants clinical history and use of internet for health information.

\begin{tabular}{|c|c|c|c|c|c|}
\hline \multirow[t]{2}{*}{ Clinical history } & \multicolumn{4}{|c|}{ Ever used internet for HI } & \multirow[b]{2}{*}{ Significance } \\
\hline & Yes & $\%$ & No & $\%$ & \\
\hline \multicolumn{6}{|c|}{ Known chronic illness } \\
\hline Yes & 51 & 79.69 & 100 & 71.43 & $x^{2}=1.56$ \\
\hline No & 13 & 20.31 & 40 & 28.57 & $\mathrm{P}=0.212$ \\
\hline \multicolumn{6}{|c|}{ No of chronic diseases } \\
\hline 1 & 10 & 76.92 & 33 & 80.49 & $x^{2}=0.08$ \\
\hline 2 or more & 3 & 23.08 & 8 & 19.51 & $\mathrm{P}=0.781$ \\
\hline \multicolumn{6}{|c|}{$\begin{array}{l}\text { Friend/relative with } \\
\text { chronic disease }\end{array}$} \\
\hline Yes & 45 & 70.31 & 110 & 78.57 & $x^{2}=1.64$ \\
\hline No & 19 & 29.69 & 30 & 21.43 & $\mathrm{P}=0.200$ \\
\hline \multicolumn{6}{|c|}{$\begin{array}{l}\text { No of visits to physician } \\
\text { last } 6 \text { months }\end{array}$} \\
\hline None & 22 & 34.38 & 30 & 21.43 & $x^{2}=5.57$ \\
\hline 1-2 times & 17 & 26.56 & 50 & 35.71 & $\mathrm{P}=0.135$ \\
\hline 3-5 times & 11 & 17.19 & 35 & 25.00 & \\
\hline More than 5 & 14 & 21.88 & 25 & 17.86 & \\
\hline \multicolumn{6}{|c|}{ Self-perceived health status } \\
\hline Coping & 7 & 10.94 & 26 & 18.57 & $x^{2}=4.30$ \\
\hline Good & 23 & 35.94 & 58 & 41.43 & $\mathrm{P}=0.231$ \\
\hline Very good & 34 & 53.13 & 55 & 39.29 & \\
\hline Poor/very poor & 0 & 0.00 & 1 & 0.71 & \\
\hline
\end{tabular}




\section{Use of internet for health information and computer/internet experience}

Binary logistic regression was also performed in order to identify computer and internet related factors that influence patients search for health information through the internet. All studied computer and/or internet experience factors were found to be significant to the use of the internet for seeking health information. This is shown in Table 4.

Table 4: Distribution of participants' computer/internet experience and use of internet for health information.

\begin{tabular}{|c|c|c|c|c|c|}
\hline \multirow[t]{2}{*}{ Computer experience } & \multicolumn{4}{|c|}{ Ever used internet for $\mathrm{HI}$} & \multirow[b]{2}{*}{ Significance } \\
\hline & Yes & $\%$ & No & $\%$ & \\
\hline \multicolumn{6}{|l|}{ Access computer at home } \\
\hline Yes & 34 & 53.13 & 26 & 18.57 & \multirow{3}{*}{$\begin{array}{l}x^{2}=25.26 \\
P=0.000^{*}\end{array}$} \\
\hline No & 30 & 46.88 & 114 & 81.43 & \\
\hline \multicolumn{5}{|l|}{ Access computer at work } & \\
\hline Yes & 41 & 64.06 & 40 & 31.01 & \multirow{2}{*}{$\begin{array}{l}x^{2}=19.19 \\
P=0.000^{*}\end{array}$} \\
\hline No & 23 & 35.94 & 89 & 68.99 & \\
\hline \multicolumn{6}{|l|}{ Frequency of computer us } \\
\hline Never & 3 & 4.69 & 61 & 43.57 & \multirow{3}{*}{$\begin{array}{l}x^{2}=38.36 \\
P=0.000^{*}\end{array}$} \\
\hline Daily bases & 27 & 42.19 & 22 & 15.71 & \\
\hline Less than $3 \mathrm{x}$ a week & 23 & 35.94 & 47 & 33.57 & \\
\hline \multirow{2}{*}{\multicolumn{5}{|c|}{ Access to smart phone }} & \\
\hline & & 96.88 & 105 & 7500 & \multirow{3}{*}{$\begin{array}{l}x^{2}=14.16 \\
P=0.000^{*}\end{array}$} \\
\hline No & 2 & 3.13 & 35 & 25.00 & \\
\hline \multicolumn{5}{|l|}{ Access to internet } & \\
\hline Yes & 64 & 100.00 & 115 & 82.14 & \multirow{3}{*}{$\begin{array}{l}x^{2}=13.02 \\
P=0.000^{*}\end{array}$} \\
\hline No & 0 & 0.00 & 25 & 17.86 & \\
\hline \multicolumn{5}{|l|}{ Source of internet } & \\
\hline Home & 52 & 81.25 & 97 & 80.83 & \multirow{5}{*}{$\begin{array}{l}x^{2}=19.21 \\
P=0.001^{*}\end{array}$} \\
\hline Work & 12 & 18.75 & 5 & 14.17 & \\
\hline Cybercafé & 0 & 0.00 & 14 & 16.67 & \\
\hline Library & 0 & 0.00 & 3 & 2.50 & \\
\hline Others & 0 & 0.00 & 1 & 0.83 & \\
\hline \multirow{2}{*}{\multicolumn{6}{|c|}{$\begin{array}{l}\text { Frequency of internet use } \\
\text { per week }\end{array}$}} \\
\hline & & & & & \\
\hline Never & 0 & 0.00 & 20 & 14.49 & \multirow{5}{*}{$\begin{array}{l}x^{2}=22.48 \\
P=0.000^{*}\end{array}$} \\
\hline 1 or $2 \mathrm{x}$ a week & 2 & 3.13 & 26 & 18.84 & \\
\hline Less than $5 \mathrm{x}$ a week & 13 & 20.31 & 20 & 14.49 & \\
\hline 5 or more a week & 5 & 7.81 & 9 & 6.52 & \\
\hline Daily bases & 44 & 68.75 & 63 & 45.65 & \\
\hline \multicolumn{6}{|l|}{ Awareness of HI online } \\
\hline Yes & 63 & 98.40 & 112 & 80.00 & \multirow{3}{*}{$\begin{array}{l}x^{2}=12.24 \\
P=0.000^{*}\end{array}$} \\
\hline No & 1 & 1.56 & 28 & 20.00 & \\
\hline \multicolumn{5}{|l|}{$\begin{array}{l}\text { Personal assessment of net } \\
\text { use skills }\end{array}$} & \\
\hline Very poor & 0 & 0.00 & 23 & 16.79 & \multirow{3}{*}{$\begin{array}{l}x^{2}=17.72 \\
P=0.001^{*}\end{array}$} \\
\hline Fair & 27 & 42.19 & 62 & 45.26 & \\
\hline Good/very good & 37 & 57.81 & 52 & 37.96 & \\
\hline
\end{tabular}




\section{Factors that affect patients online health information seeking}

Factors that affect online health information seeking among patients were identified in this study. In controlling for other factors, the multiple logistic regression output shown in Table 5 revealed that, employment, average monthly income above GHS1000 and computer ownership at home were significant factors that affect the use of internet for health information purposes. As compared to individuals who were employed, individuals who were students and employed at the same time, had lesser odds of using the internet for health information purposes $(\mathrm{OR}=0.05, \mathrm{CI}=0.01-0.40$, $\mathrm{p}=0.004)$. Participants whose average monthly income is above GHS 1000 and those who owned personal computers at home had higher odds of using internet for seeking health information $(\mathrm{OR}=12.34, \mathrm{CI}=1.87-81.55, \mathrm{P}=0.009)$ and $(\mathrm{OR}=5.23, \mathrm{CI}=1.47-18.50, \mathrm{P}=0.011)$ respectively (Table 5).

Table 5: Factors that affect patient online health information seeking behaviour, results of Bivariate and Multivariate logistic regression

\begin{tabular}{|c|c|c|c|c|}
\hline Variables & UOR $(95 \% \mathrm{CI})$ & P-value & AOR (95\% CI) & P-value \\
\hline Age & $1.00(0.99-1.02)$ & 0.962 & $0.97(0.93-1.01)$ & 0.203 \\
\hline \multicolumn{5}{|c|}{ (2) } \\
\hline Male & Ref & & & \\
\hline Female & $0.53(0.29-0.96)$ & 0.039 & $0.53(0.18-1.61)$ & 0.268 \\
\hline Education & $3.78(2.23-3.69)$ & 0.000 & $1.32(0.40-4.34)$ & 0.646 \\
\hline \multicolumn{5}{|l|}{ Employment } \\
\hline Employ & Ref & & & \\
\hline Unemployed & $0.19(0.06-0.58)$ & 0.004 & $2.30(0.06-83.7)$ & 0.649 \\
\hline Retired & 1 & & 1 & \\
\hline Student and employed & $1.90(0.82-4.37)$ & 0.134 & $0.05(0.01-0.40)$ & $0.004^{*}$ \\
\hline \multicolumn{5}{|l|}{ Average monthly income } \\
\hline $500-1000$ & $2.89(1.24-6.72)$ & 0.014 & $1.68(0.81-13.98)$ & 0.093 \\
\hline$\geq 1000$ & $6.00(2.34-15.41)$ & 0.000 & $12.34(1.87-81.55)$ & $0.009 *$ \\
\hline Have PC at home & $4.97(2.59-9.52)$ & 0.000 & $5.23(1.47-18.60)$ & $0.011^{*}$ \\
\hline Have PC at work & $3.97(2.11-7.46)$ & 0.000 & $1.88(0.59-5.98)$ & 0.286 \\
\hline PC use skills & $3.11(2.07-4.69)$ & 0.000 & $2.31(0.91-5.86)$ & 0.079 \\
\hline$P C$ use frequency & $1.89(1.37-2.60)$ & 0.000 & $1.29(0.71-2.34)$ & 0.396 \\
\hline Have smart phone & $10.33(2.40-44.46)$ & 0.002 & $15.5(0.82-293.2)$ & 0.067 \\
\hline Aware HI on internet & 1 & & & \\
\hline Source of internet & $0.65(0.39-1.07)$ & 0.092 & $1.70(0.47-6.21)$ & 0.420 \\
\hline Internet use frequency & $1.69(1.31-2.20)$ & 0.000 & $0.72(0.34-1.52)$ & 0.385 \\
\hline Barriers in search & $0.84(0.65-1.09)$ & 0.196 & $0.85(0.55-1.32)$ & 0.476 \\
\hline \multicolumn{5}{|c|}{ Barriers in internet access } \\
\hline Cost of internet & $0.89(0.47-1.68)$ & 0.720 & $1.01(0.36-2.86)$ & 0.982 \\
\hline Infrequent power & $0.58(0.14-2.32)$ & 0.439 & $0.63(0.09-4.37)$ & 0.642 \\
\hline Use causes anxiety & $0.82(0.57-1.18)$ & 0.286 & $0.27(0.06-1.32)$ & 0.106 \\
\hline
\end{tabular}




\section{Discussion}

Studies have shown that there is an increasing interest in health information among the general population and the internet has become an important source in recent times [16]. Out of 204 participants interviewed in this study, 175 of them representing $85.8 \%$ reported ever using the internet for one or more purpose. All participants who reported ever using the internet were also aware of the availability of health information online. The high coverage of internet use is evident of the increasing demand and use of internet in developing countries [17]. This finding is not surprising, considering the rising popularity of the Internet and the ease of access by android, IOS, and Microsoft powered smartphones and other hand-held devices.

Despite the high internet use and awareness of the availability of health information on the internet among participants, only 64 of them (31.37\%) indicated ever using the internet for health related purposes. This finding is higher compared to a study conducted among patients attending Korle$\mathrm{Bu}$ Teaching Hospital where internet access was $35.7 \%$ and internet use for health information purposes was $15.7 \%$ [8]. The difference in rates in these studies can be attributed to the increased rate of technology penetration and internet usage among the population over time. Also, compared to our findings, internet usage rate of $67.7 \%$ for health related purposes was found among students in a Ghanaian [1]. The authors indicated the high rate among students could be due to high access to Wi-Fi on the university campuses. A similar study conducted in Kuwait among patients also revealed that, $62.9 \%$ of patients used the internet for obtaining health related information [16].

There is discrepancy in the low internet use for health information purposes in this study as compared to the high internet access and awareness of the availability of health information on the internet. Just as in many parts of developing countries, awareness and availability of information does not often imply access and use [18]. This is particularly so since the possession and access to internet-ready devices such as computers at work or home and particularly smart phones is as high as $81.86 \%$. The Internet has the potential to critically change the doctor-patient relationship, in that it offers an opportunity for patients to increase their knowledge, become more informed and increase their involvement in the health care decision-making process [19]. It is unclear if health workers in the study site also access health information using the internet. Health workers with such skills could play an essential role in assisting, educating and motivating their clients about health information on the internet.

Many factors have been determined to influence online health information seeking [16]. Just as revealed in other research findings, women in this study were more likely than men to search for health information using the internet. Also, online health information seekers were mostly educated, employed, earn more income and have access to smart phone and computer at home and at work $[2,8,16,17]$. The likely reason for females being more likely to search online for health information than males can be attributed to the fact that, males often use the internet for entertainment purposes and females are much concerned about their health and that of their children or relatives [20]. Also, being employed and earning more income ensures that individuals are capable of acquiring internet-ready devices such as smart phones and laptops. Educated people may be more aware of information sources other than health care professionals and may not hesitate to use them especially when they are not satisfied with the information given by health 
care professionals. They are also likely to be able to interpret and understand information they read from the internet [21].

Similar to other study findings [16], age, marital status, parental status and religion in this study, were found not to be significantly associated with the use of internet for health information purpose. This finding however does not agree with other studies [2,21]. For age, marital and parental status, the difference in results between the two studies could be attributed to the fact that, majority of participants in this study were young people who are not likely to search for health information online but would rather use the internet for entertainment and other purposes and also because they are mostly free from chronic illnesses compared to the aged [22]. It is also important to note that, most of the young persons in this study were males who are not likely to use internet for health information compared to the females. Having greater number of children is said to influence online health information search in order to meet their health needs [2]. In this study, only a few study participants reported having more than 3 children which could explain the nonsignificant association with internet use for health information.

Findings on the influence of health insurance on health information seeking behaviour on the internet are contradictory. A higher probability of using the internet for health information purposes was found among state insured individuals [23]. In contrast, a related study revealed a higher probability among individuals with private health insurance [24]. In this study, there was no significant association between national health insurance status and health information access using the internet. The association was however significant for private health insurance and the use of internet for health information purposes. The relationship between health information seeking through the internet and health insurance status is attributed to the amount spent on seeking health care. Where out of pocket payment and private insurance are costly, there are financial constraints to accessing health care services and hence individuals may seek health information through other means including the internet [2]. Ghana has a nation-wide national health insurance coverage. This could partly explain why there was an association between use of internet for health information and subscribing to private health insurance.

The health status of some people may require more care than the general population. With increased use of technology in the general population, it is expected that more patients will begin to accept e-health in order to save time, reduce costs and avoid inconvenience [4,24]. A finding in this study that is inconsistent with earlier studies [2,21] indicates that, patients' clinical history such as having a chronic disease or a relative/friend having a chronic disease, number of chronic diseases, health status of patients and number of visits to a clinician were statistically insignificant with the use of internet for health information purposes. This finding in our study however conforms to a study conducted among patients in Kuwait where none of the variables relating to patients' clinical history was proved to affect online health information seeking [16]. It is worth noting that majority of participants were young with mean age of 37.7 years. The insignificant association in our study may partly be explained by the association between age and these clinical characteristics as older individuals tend to have poor health, chronic illnesses and access health services more $[17,20]$.

People who have access to computer and internet at home or work will generally be more knowledgeable and experienced in using the computer in different daily activities including 
searching for information. Findings from studies conducted by $[16,19,21]$ showed that, computer and internet experience are significantly associated with health information access from the internet. Consumers having access to computers and internet from home or office, were more likely than others to use the internet for health information purposes. The study also revealed that, internet usage skills and time spent on the internet increases chances of health information seeking on the internet. The authors established that these variables were linked to each other as having access to a computer and internet and being experienced in using the internet, provides the freedom to use this resource anytime and hence the likelihood of searching for other information including health information. This is also evident in a study conducted among university students in Ghana where students who used the internet on a daily bases also used the internet for health purposes [1]. Our findings on computer \& internet experience and the search for health information using the internet, strongly conform with these earlier studies, as all computer and internet experience variables showed a significant association with searching for health information online. Having good internet usage skills also enables refined searches to be conducted in order to find accurate results to the questions. This in turn serves as a motivation for more internet search.

In the present study after adjusting for confounding effects, employment status, average monthly income and ownership of computer at home were proven to be significant factors that affect patients search for health information using the internet. Several studies among others have reported similar findings, this seems to represent a global public health problem [2,8,21]. This shows a health information seeking behaviour only among the middle to higher class of society compared to persons of lower social class who are unemployed, earn less income and do not own a computer. Despite having less access to health care, persons of lower social standing tend to have limited access to internet resources that could lessen their health care burden. Thus, to reduce inequalities in health and achieve universal access to health, the differences of health information seeking behaviour using the internet must be minimized through public health actions.

\section{Limitations}

Firstly, this cross sectional study provides a snapshot during the study period, on patients' online health information seeking behaviour. Further longitudinal studies are needed to unravel changes in patterns of internet use among patients. Secondly, responses provided were that of individual patients based on their understanding of questions posed by the researcher. Even though questions were posed in simple terms and in language patient understands, their understanding may influence responses especially patients who are not formally educated. Thirdly, the study did not point out the type of information and websites information is obtained from in order to determine its accuracy.

\section{Conclusions and Recommendations}

This study was conducted in order to identify factors influencing online health information seeking behaviours among patients in Kwahu West Municipal. Findings revealed that, internet usage rate among patients was $85.8 \%$. However, only $35.7 \%$ of patients ever used the internet to access health information. Sex, education and use of private health insurance were significant factors that influence Health Information Seeking Behaviour (HISB) using the internet. The study also showed that, computer and internet experience factors also increased the probability of using internet for 
health information. An important finding of this study is that being employed, earning higher income and owning a computer at home are positive predictors of health information seeking behaviour using the internet. This simply implies that, one's ability to afford internet-ready gadgets affects the use of internet for health information purposes. It is important to explore other means of reducing this disparity in information access by improving skill and health literacy, especially among the low social class who cannot afford internet ready devices.

Based on the findings of the study, the following recommendations were made;

1. Primary health care providers in the municipality should recognize that patients are using the internet for health information and should be prepared to assist, encourage, motivate and promote internet user skills among their patients. This will increase patient involvement in care and improve treatment outcomes.

2. Further research is needed to ascertain the impact of internet use for health information purposes among patients. Studies to determine if health workers in the municipality use internet for health information purposes and if they possess the necessary skills to guide patients in the search for health information is also necessary.

\section{Conflict of interest}

The authors declare no potential conflict of interests with respect to the study, authorship and/or publication of this article.

\section{References}

1. Osei Asibey B, Agyemang S, Boakye Dankwah A. 2017. The Internet Use for Health Information Seeking among Ghanaian University Students: A Cross-Sectional Study. Int J Telemed Appl. 2017, 1756473. doi:https://doi.org/10.1155/2017/1756473. PubMed

2. Nölke L, Mensing M, Krämer A, Hornberg C. 2015. Sociodemographic and health(care-)related characteristics of online health information seekers: a cross-sectional German study. BMC Public Health. 15(1). doi:https://doi.org/10.1186/s12889-015-1423-0. PubMed

3. Johnston AC, Worrell JL, Di Gangi PM, Wasko M. 2013. Online health communities. Inf Technol People. 26(2), 213-35. doi:https://doi.org/10.1108/ITP-02-2013-0040.

4. World Health Organization. Global diffusion of eHealth making universal health coverage achievable. Report of the third global survey on eHealth. Geneva: 2016.

5. World Health Organization. Safety and security on the Internet - Challenges and advances in Member States: based on the findings of the second global survey on eHealth. Geneva: World Health Organization, 2011.

6. Wu D, Li Y. 2016. Online health information seeking behaviors among Chinese elderly. Libr Inf Sci Res. 38(3), 272-79. doi:https://doi.org/10.1016/j.lisr.2016.08.011. 
7. Xiao N, Sharman R, Rao HR, Upadhyaya S. 2014. Factors influencing online health information search: An empirical analysis of a national cancer-related survey. Decis Support Syst. 57, 417-27. doi:https://doi.org/10.1016/j.dss.2012.10.047.

<jrn>8. Kyei MY, Clegg-Lamptey JN, Ampaw-Asiedu D, Kyei JM. Health Information Seeking Using the Internet by Patients Attending a Surgical Care Department in a Tertiary Hospital in Sub-Sahara Africa. Postgraduate Medical Journal of Ghana. 2016; 5(1).</jrn>

9. Cotten SR, Gupta SS. 2004. Characteristics of Online and Offline Health Information Seekers and Factors That Discriminate Between Them. Soc Sci Med. 59(9), 1795-806. doi:https://doi.org/10.1016/j.socscimed.2004.02.020. PubMed

10. Johnson JD. 2014. Health-related information seeking: Is it worth it? Inf Process Manage. 50(5), 708-17. doi:https://doi.org/10.1016/j.ipm.2014.06.001.

11. Obasola OI, Agunbiade OM. 2016. Online Health Information Seeking Pattern Among Undergraduates in a Nigerian University. SAGE Open. 6(1). doi:https://doi.org/10.1177/2158244016635255.

12. Ghana Health Service. THE HEALTH SECTOR IN GHANA: FACTS AND FIGURES. Centre for Health Information Management (CHIM) under the Policy Planning Monitoring and Evaluation Division (PPMED), 2018.

13. Borzekowski DL, Fobil JN, Asante KO. 2006. Online Access by Adolescents in Accra: Ghanaian Teens' Use of the Internet for Health Information. Dev Psychol. 42(3), 450-458. $\underline{\text { PubMed }}$

14. Zurek K. Over 10 million Ghanaians use the internet - Report. Graphic Online. Feb 19, 2018.

15. Cochran WG. Sampling techniques. 3rd ed. New York, NY: Wiley; 1977.

16. Alkhatlan HM, Rahman KF, Aljazzaf BH. 2018. Factors affecting seeking health-related information through the internet among patients in Kuwait. Alexandria Journal of Medicine. 54(4), 331-36. doi:https://doi.org/10.1016/j.ajme.2017.05.008.

17. Dickerson S, Reinhart AM, Feeley TH, Bidani R, Rich E, Garg VK, Hershey CO. 2004. Patient Internet Use for Health Information at Three Urban Primary Care Clinics. J Am Med Inform Assoc. 11(6). PubMed

18. Odutola AB. 2003. Developing Countries Must Invest in Access to Information for Health Improvements. J Med Internet Res. 5(1), e5. doi:https://doi.org/10.2196/jmir.5.1.e5. PubMed

19. Yusuf AA, Alhaji AA. 2015. Knowledge, attitude, and use of internet for medical information by patients attending specialist clinics in ABUTH Zaria-Nigeria. Sub-Saharan African Journal of Medicine. 2(4), 160. doi:https://doi.org/10.4103/2384-5147.172435. 
20. Higgins O, Sixsmith J, Barry MM, Domegan C. A literature review on health information seeking behaviour on the web: a health consumer and health professional perspective. ECDC. 2011. doi: $10.2900 / 5788$.

21. TURGUT EÇ. ONLINE HEALTH INFORMATION SEEKING HABITS OF MIDDLE AGED AND OLDER PEOPLE: A CASE STUDY. GRADUATE SCHOOL OF INFORMATICS: THE MIDDLE EAST TECHNICAL UNIVERSITY; 2010.

22. Johnson E, Johnson CS. 2016. Internet Use and Access to Health Information among Canadians: Are the Elderly on the Sidelines? J Gerontol Geriatr Res. 05(06). doi:https://doi.org/10.4172/2167-7182.1000367.

23. Ayers SL, Kronenfeld JJ. 2007. Chronic illness and health-seeking information on the Internet. Health. 11(3), 327-47. doi:https://doi.org/10.1177/1363459307077547. PubMed

24. Houston TK, Allison JJ. 2002. Users of Internet health information: differences by health status [Internet]. J Med Internet Res. 4(2), e7. https://doi.org/10.2196/jmir.4.2.e7 PubMed 